\title{
Cooling cows with sprinklers: Effects of soaker flow rate and timing on behavioral and physiological responses to heat load and production
}

\author{
Grazyne Tresoldi, ${ }^{1 *}$ Karin E. Schütz, ${ }^{2}$ and Cassandra B. Tucker ${ }^{1} \dagger$ \\ ${ }^{1}$ Center for Animal Welfare, Department of Animal Science, University of California, Davis 95616 \\ ${ }^{2}$ AgResearch Ltd., Hamilton 3240, New Zealand
}

\section{ABSTRACT}

Spray strategies (e.g., flow rate and spray timing) may affect the surrounding microclimate and how cows use soakers, affecting cooling efficiency. Our objective was to evaluate the combined effects of spray timing (i.e., frequency, low: $3 \mathrm{~min}$ on, $6 \mathrm{~min}$ off; or high: 1.5 min on, 3 min off) and flow rates (3.3 or $4.9 \mathrm{~L} / \mathrm{min})$ on behavioral and physiological responses to heat load and production in Holstein cows managed in a freestall barn. In a $2 \times 2$ Latin square design, 3 cohorts of 4 pairs of cows averaging ( \pm standard deviation) $36.7 \pm$ $5.4 \mathrm{~kg} / \mathrm{d}$ of milk were tested for $3 \mathrm{~d} /$ treatment. Water was sprayed at the feedline from 0815 to $2330 \mathrm{~h}$ when air temperature and relative humidity averaged $27 \pm$ $3^{\circ} \mathrm{C}$ and $37 \pm 7 \%$, respectively. The overall quantity of water sprayed was not affected by spray timing; it varied only as a function of flow rate. Cows' posture and location within the pen were measured continuously, whereas feeding and body temperature were recorded every 3 min over $24 \mathrm{~h} / \mathrm{d}$. Respiration rates were recorded daily every 45 min from 0900 to 2000 h. Neither spray timing nor flow rates affected posture, location in the pen, feeding activity, or respiration rates. Overall, on average, cows spent $12.6 \pm 0.4 \mathrm{~h} / \mathrm{d}$ lying down and 5.8 $\pm 0.3 \mathrm{~h} / \mathrm{d}$ in the feed bunk area. While in the feed bunk area, cows spent $78 \pm 3 \%$ of their time feeding. Average respiration rate ranged from 57 to $59 \pm 3$ breaths/min across treatments. Although body temperature tended to be reduced when using higher flow rate, this difference was $0.1^{\circ} \mathrm{C}$ when comparing 24-h averages (4.9 vs. $3.3 \mathrm{~L} / \mathrm{min}: 38.6$ vs. $\left.38.7 \pm 0.1^{\circ} \mathrm{C}\right)$. Body temperature differences, however, were more marked and statistically different when soakers were cycling, especially between 1100 and 2200 h. Despite this, the magnitude of the hourly differences were $<0.2^{\circ} \mathrm{C}$. Milk production also

\footnotetext{
Received April 20, 2018.

Accepted August 23, 2018.

*Present address: College of Agriculture, California State University, Chico 95929.

†Corresponding author: cbtucker@ucdavis.edu
}

tended to increase by $1.5 \mathrm{~kg} / \mathrm{d}$ when using higher flow rates. When using the same water volume, spray timing did not affect cow behavior, physiology, or production. Flow rate had a small effect on milk production and body temperature but the biological relevance of these differences is unclear, especially in this situation where all cows were relatively cool.

Key words: soaker, heat stress, cooling strategy, time on and off

\section{INTRODUCTION}

In warm weather, cows adjust their behavior and physiology in attempt to cope with the heat load. Cows often seek cooler microclimates or protection against solar radiation (Mader et al., 2007; Tucker et al., 2008; Schütz et al., 2009), reduce their lying and feeding times (Chen et al., 2013), and increase their respiration rates (RR), which often is accompanied by panting (Gaughan and Mader, 2014; Tresoldi et al., 2016). Cows may also experience elevated body temperature (BT, Kendall et al., 2007; Chen et al., 2013), infertility (Huang et al., 2009; Schuller et al., 2014), and production losses (Bohmanova et al., 2007; Wheelock et al., 2010) when exposed to warm conditions.

To minimize the negative effects of the hot weather, approximately $75 \%$ of the large dairies in United States (herd $\geq 500$ cows) spray their cattle with water to relieve heat stress during the summer (USDA, 2016). In these dairies, soakers or misters are often used at the holding area at the milking parlor, and in the home pen either over the feed bunk or lying areas (Anderson et al., 2013; Tresoldi et al., 2017). Although dairies spray their cattle with water, economic losses associated with heat load indicate a problem is ongoing in the US dairy industry (St-Pierre et al., 2003; von Keyserlingk et al., 2013). In a survey conducted in 10 California drylot dairies during the summer, we found that farms used from 2.3 to $25.6 \mathrm{~L}$ of water/h per cow in their home pen (Tresoldi et al., 2017). In these same 10 dairies, cattle RR varied from 65 to 95 breaths/min, suggesting there are likely opportunities to improve the efficiency of water use and cow cooling. 
The quantity of water used to cool cattle depends upon spray management decisions including nozzle flow rate, activation temperature threshold, and the on and off timing. Although these factors, themselves, can affect cooling effectiveness, the combined effects of altering water volume on cow cooling in the literature is mixed. For example, when cows were forced to use soakers, they were cooler when water was sprayed for longer or off times were reduced (approximately 9 vs. $25 \mathrm{~L} / \mathrm{h}$, Flamenbaum et al., 1986; 1.7 vs. $5.2 \mathrm{~L} / \mathrm{h}$, Brouk et al., 2003; 20 vs. 33 L/h, Tresoldi et al., 2018). Another study found that using nozzles delivering $\geq 1.3$ $\mathrm{L}$ of water/min (16 vs. $59 \mathrm{~L} / \mathrm{h}$ ) resulted in no changes in BT (Chen et al., 2015).

The cooling success of the spray strategies can also be affected by how cows use them. For example, although sprayed water more effectively reduces heat load in cattle compared with shade alone (e.g., lower BT; Kendall et al., 2007; Chen et al., 2013, 2016b), cows would rather use shade than sprinklers provided in the sun (Schütz et al., 2011). This is likely because cows are highly motivated to use shade (Schütz et al., 2008). When considering behavioral responses to spray, the effects of flow rates have been examined (Chen et al., 2016a,b,c). No overall changes in spray use and cooling were observed when using spray nozzles delivering $\geq 1.3 \mathrm{~L}$ of water/min over $24 \mathrm{~h}$ (Chen et al., 2016b). However, cows tended to lower their heads to enter (Chen et al., 2016b,c) and waited until the water was turned off to exit the spray area (Chen et al., 2016b). The latter result may suggest that timing can affect when cows leave the spray area, and consequently, how cows use this resource and its effectiveness. In addition, spraying water cools the microclimate (Tresoldi et al., 2018), possibly attracting cows to this area (Mader et al., 2007; Chen et al., 2013).

The objective of this study was to measure the combined effects of flow rates and spray timing (i.e., frequency) on behavior, physiology, and production of dairy cows housed in a freestall barn. We predicted that flow rate would have no effect on behavior, physiology, or milk production. On the other hand, we expected that spray timing would affect cows' behavior: when water is sprayed more often, cows would spend more time at the feed bunk area, and consequently, this would improve cooling benefits and milk production.

\section{MATERIALS AND METHODS}

\section{Animals and Housing}

This study was carried out between July and September of 2016 at the University of California-Davis Dairy Teaching and Research Facility. All procedures were approved by the University of California-Davis Institutional Animal Care and Use Committee. Twenty-four Holstein cows were used with average milk yield $( \pm \mathrm{SD})$ $36.7 \pm 5.4 \mathrm{~kg} / \mathrm{d}$, DIM $232 \pm 64$, and parity of $2 \pm 1$ lactations. The average number of days carrying calf was $107 \pm 51$ for the 22 pregnant cows used. Cows were housed in pairs balanced for milk production $(\mathrm{n}=12$ pairs). We tested 4 pairs of cows at a time, resulting in 3 cohorts of 8 cows.

The 4 pairs were housed in pens divided by removable fencing panels (Power River, Provo, UT) and plywood sheets at the feed bunk area $(2.4 \mathrm{~m}$ tall $\times 3.7 \mathrm{~m}$ long) as described in Figure 1. In each pen, cows had access to 4 shaded sand-bedded stalls, a water trough, and a shaded feed bunk ( $4.9 \mathrm{~m}$ long), located at 7.5 $\mathrm{m}$ from the lying area. Each bunk consisted of 5 feed bins; however, feed was delivered in only 3 of them. The spray water line was fitted above the feed bins (1.9 $\mathrm{m}$ above the ground) and contained a solenoid, a 207$\mathrm{kPa}$ pressure regulator (PR55-30, Hendrickson Bros., Corona, CA), and 2 spray nozzles (described below). The nozzles were angled to soak the cows' back from withers when feeding, reaching up to $1.8 \mathrm{~m}$ away from the feed bunk. Two fans were located over the lying area. Cows were fed TMR ad libitum 4 times daily (at approximately $0400,1000,1600$, and $2200 \mathrm{~h}$ ), and milked twice a day (0400 and $1600 \mathrm{~h}$ ).

\section{Experimental Design}

In a $2 \times 2$ Latin square design, we tested the combined effects of 2 flow rates and spray frequencies. The spray nozzles used delivered either 3.3 or $4.9 \mathrm{~L}$ of water/min (TF-VP 5 and 7.5, respectively, Turbo FloodJet wide angle flat spray tip, Spraying Systems Co., Wheaton, IL). These nozzles types deliver large droplets and are common on California farms (G. Tresoldi, unpublished data). Timing varied in minutes water was on (i.e., spray duration): 1.5 or $3 \mathrm{~min}$, and off: 3 or 6 min, respectively, resulting in a high and low frequency treatments (i.e., 10 vs. 5 cycles $/ 45 \mathrm{~min}$ ). These 2 timing treatments were chosen because they reduced BT after $45 \mathrm{~min}$ (G. Tresoldi, unpublished data), and they delivered the same water volume throughout the day. In this study, differences in water volume resulted from different flow rates used: 990 and 1,470 L of water/ nozzle per day, respectively, for 3.3 or $4.9 \mathrm{~L}$ of water/ min. For ethical reasons, we did not included an uncooled treatment (i.e., shade only). Others have shown that cows prefer to use shade and sprayed water compared with shade alone (Chen et al., 2013), and when forced to use only the latter their BT could reach up to $40.0^{\circ} \mathrm{C}$ (Tarazon-Herrera et al., 1999; Correa-Calderon et al., 2004; Chen et al., 2013). This temperature is 
much higher than described elsewhere for fever (e.g., $\geq 39.3^{\circ} \mathrm{C}$; Benzaquen et al., 2007; Reece, 2015). Given that shade alone is insufficient to cool cows, we did not want to repeat a treatment that has negative effects for the animals and is already well characterized elsewhere in the literature.

Each pair of cows was housed together $3 \mathrm{~d}$ before the beginning of data collection. During the first 2 habituation days, cows were exposed to each spray frequency

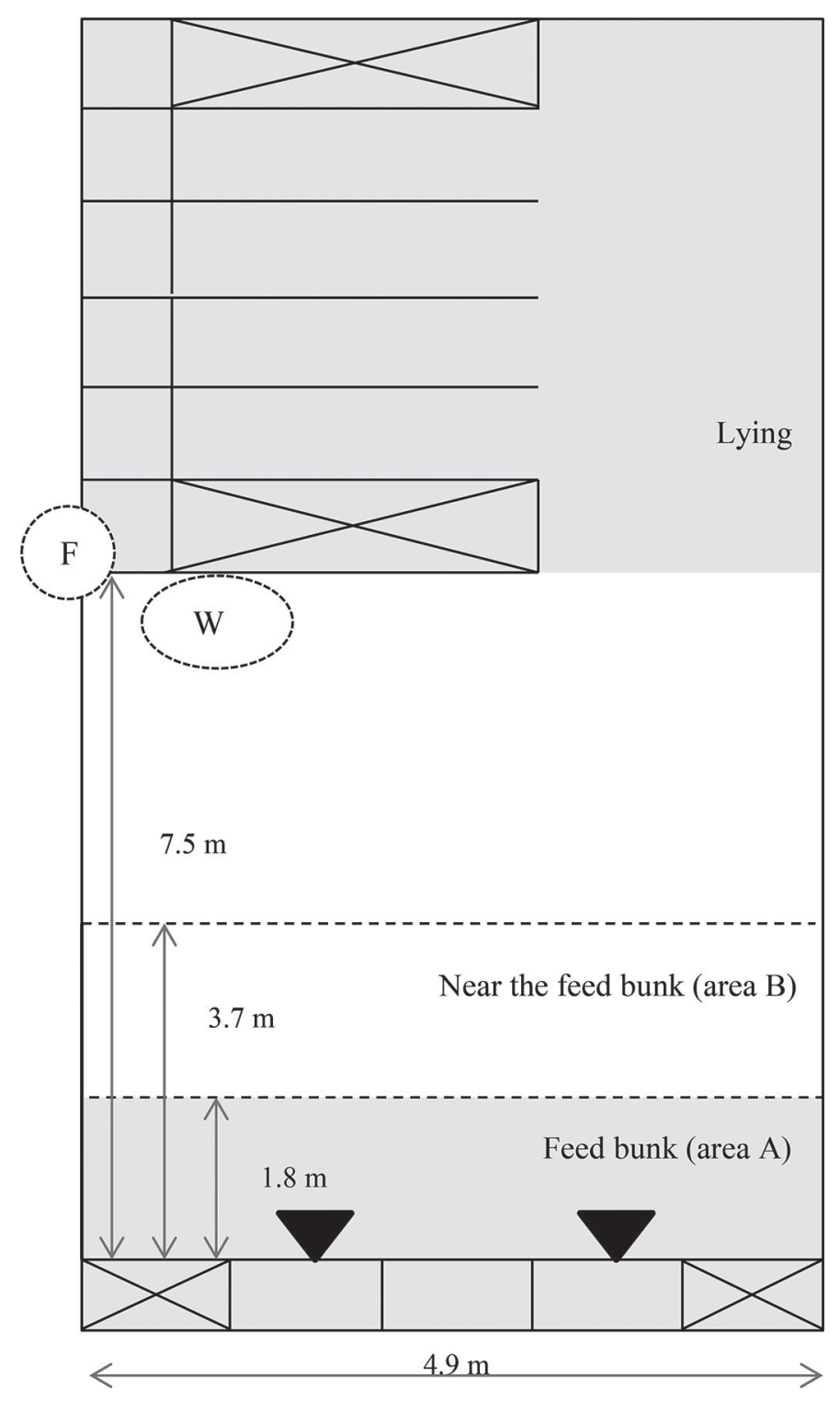

Figure 1. Pen diagram (not to scale) that housed each pair of cows ( 1 of 4 pens). Lying and feed bunk areas were shaded. In the feed bunk (area A), cows had access to 3 feed bins and 2 soaker nozzles $(\boldsymbol{\nabla})$. This area was enclosed by a $3.7-\mathrm{m}$-long plywood sheet, which extended to the space near the feed bunk (area B). Water trough and fan locations are indicated by $(\mathrm{W})$ and $(\mathrm{F})$, respectively. Crossed-out areas represent no cow access. treatment using the higher flow rate. On the third day, cows received spray as per the farm protocol $(4.9 \mathrm{~L}$ of water $/ \mathrm{min}, 1.5 \mathrm{~min}$ on and $5 \mathrm{~min}$ off). Treatments were applied for $3 \mathrm{~d}$ at a time, for a total of $12 \mathrm{~d}$ per cohort. The order that each pair received each treatment in each cohort was balanced. They were randomly chosen without replacement using unique permutations. Water was sprayed from 0815 to $2330 \mathrm{~h}$, except from 1545 to $1645 \mathrm{~h}$ (afternoon milking), and was controlled by a cycle timer (custom; Chipponeri Electric Inc., Hilmar, $\mathrm{CA})$ that triggered the solenoid in the water line. Although farmers usually rely on air temperature (AT) to trigger spray activation, we chose to spray cows in a fixed schedule to ensure all groups of cows received all the treatments for the same number of hours every day. Our group has shown that cows prefer to use soakers compared with shade alone when $\mathrm{AT}$ is $\sim 22$ to $23^{\circ} \mathrm{C}$ (Chen et al., 2013). Thus, the time range chosen in our study was based on weather data obtained in 2015 at the same location when AT was $\geq 22^{\circ} \mathrm{C}$.

\section{Physiological Measures}

Respiration rate was recorded every $45 \mathrm{~min}$ from 0900 to $2000 \mathrm{~h}$, excluding afternoon milking. We measured the time for 10 flank movements and converted it to breaths per minute. Data were collected by 13 observers; inter-observer reliability was calculated using regression analysis for $\mathrm{RR}\left(\mathrm{R}^{2} \geq 0.98, \quad P<0.001\right.$; intercept $=-0.22$ to $0.19, P \geq 0.05$; slope $=0.96$ to $1.02, P \geq 0.05$ ).

Body temperature was recorded intravaginally every $3 \mathrm{~min} 24 \mathrm{~h} / \mathrm{d}$ using data loggers (DST centi-T, accuracy: $\pm 0.1^{\circ} \mathrm{C}$, resolution: $\pm 0.032^{\circ} \mathrm{C}$; Star-Oddi, Gardabaer, Iceland) attached to a shortened, hormone-free controlled internal drug release insert (DEC International NZ Ltd., Hamilton, New Zealand).

\section{Behavioral Measures}

All pens were recorded continuously $24 \mathrm{~h} / \mathrm{d}$ with 18 video cameras (WV-BP334 black-and-white CCTV video cameras, Panasonic Corp. of North America, Secaucus, NJ) placed above the feed bunk (11 cameras, 2.5 to $3.3 \mathrm{~m}$ above the floor), lying (4 cameras, 2.5 to $2.7 \mathrm{~m}$ above the floor), and unshaded areas (3 cameras, 2.9 to $3.1 \mathrm{~m}$ above the floor). All cameras were set to record at medium quality ( 15 frames/s) and were connected to a digital video recorder with surveillance software (GV Surveillance System version 8.4, GeoVision Inc., Taipei, Taiwan). Red lights were mounted above the feed bunk area for nighttime visibility. Lying areas were illumined $24 \mathrm{~h} / \mathrm{d}$ with fluorescent tubes. 
Individual cows were identified by their coat patterns and collars with reflective tape. Lying (flank or chest in contact with the ground or bedding) and use of feed bunk and neighboring areas were recorded continuously (with 24-h periods beginning at $0400 \mathrm{~h}$ ). A cow was recorded in the feed bunk (area A) when the majority of her body was within $1.8 \mathrm{~m}$ from the head gates, which was delimited by a painted line on the ground. To capture cows that could be benefiting from small droplets away from the direct spray, we measured when the majority of the cow's body was within $\sim 2$ m near to the feed bunk (area B, Figure 1). If a cow was evenly distributed between the feed bunk area and its vicinity, her location was determined by her front hooves or head direction. Using continuous data, we determined the duration of each visit or lying bout, the total number and duration cows spent in each area and lying down. In addition, from the time cows were observed in the feed bunk (area A), videos were scanned starting $30 \mathrm{~s}$ after the beginning of the bout and, then, every 3 min to record whether they were feeding (cow's head was past the head gates at the feed bunk, and her mouth was directed toward the bottom of the feed bin, or she was chewing visible feed, i.e., had feed inside or around her mouth; watched for up to $20 \mathrm{~s}$ ). Data were recorded by 17 observers. Inter-observer reliability was calculated using kappa coefficient for each measure $(\kappa$ $\geq 0.91)$.

\section{Milk Production}

Milk production data were measured (Metatron P21, GEA-WestfaliaSurge, Düsseldorf, Germany) and obtained through DairyComp 305 (Valley Agricultural Software, Tulare, CA).

\section{Sprayed Water Measures}

Sprayed water temperature was measured at the nozzle outlet during the first spray cycle in the morning $(0815 \mathrm{~h})$ and after milking (1645 h) using a thermocouple (HTTC36-T-116G-2) connected to a temperature data logger (OM-CP-TC101A) stored in a waterproof case (OM-CP-WATERBOX101A, all products Omega Engineering Inc., Stamford, CT).

The flow rate was only measured for $3 \mathrm{~d}$ after the end of the experiment from 0900 to 1945 h. Each pen was sampled once within a 45 -min interval by collecting the spray into a bottle for $5 \mathrm{~s}$ at the beginning of the cycle ( $\mathrm{n}=45$ measurements/pen or $\mathrm{n}=90$ measurements/flow rate). We used this approach to guarantee all droplets would be captured in the bottle as soon as the spray started. The water was weighed and the flow rate estimated.

\section{Environmental Conditions}

Weather. A portable weather station (WS-16, Novalynx Corp., Auburn, CA) was placed in an open area nearby (approximately $50 \mathrm{~m}$ away). Air temperature $\left({ }^{\circ} \mathrm{C}\right)$, black globe temperature $\left(\mathbf{B G T},{ }^{\circ} \mathrm{C}\right)$, wind speed (WS, m/s), relative humidity $(\mathbf{R H}, \%)$, solar radiation $\left(\mathrm{W} / \mathrm{m}^{2}\right)$, and precipitation $(\mathrm{mm})$ were recorded every $5 \mathrm{~min}$. Additional measures of heat load were temperature-humidity index (THI) and heat load index (HLI), using the following equations from Kelly and Bond (1971) and Gaughan et al. (2008), respectively:

$$
\begin{gathered}
\mathrm{THI}=(1.8 \times \mathrm{AT}+32)-[(0.55-0.0055 \times \mathrm{RH}) \\
\times(1.8 \times \mathrm{AT}-26)] \\
\mathrm{HLI}=\text { if }[\mathrm{BGT}>25,8.62+(0.38 \times \mathrm{RH}) \\
+(1.55 \times \mathrm{BGT})+\exp (-\mathrm{WS}+2.4)-0.5 \times \mathrm{WS}], \\
\text { else }[10.66+(0.28 \times \mathrm{RH})+(1.3 \times \mathrm{BGT})-\mathrm{WS}] .
\end{gathered}
$$

Pen Microclimate. Air temperature in the lying and feed bunk areas were measured every 3 min using temperature-humidity data loggers (HOBO U23-002 logger with RS3 solar radiation shields, Onset Computer Corp., Pocasset, MA). To avoid cows interacting with the equipment, these sensors were mounted on the ceiling (2.7 $\mathrm{m}$ above the floor in the lying areas) or on the inner side of the feed bins in each pen.

\section{Data Management and Statistical Analysis}

Due to spray malfunction, $1 \mathrm{~d}$ was excluded from data analysis. In addition, data from 3 cows were not used: 2 due to lameness, and another because she stood in the water trough. Milk production data were partially missing for 10 of the 12 pairs for up to $4 \mathrm{~d}$. However, each pair had at least 1 measurement recorded per treatment, and the missing data were evenly distributed among treatments (total records per treatment ranged from 29 to 32 ).

Statistical procedures were carried out using SAS (SAS Institute Inc., 2014). All data were screened to confirm the normality and homoscedasticity of variances. Milk production and behavioral and physiological measures were calculated per each cow per day. These 24 - $h$ values were averaged per cow pair $(n=12)$, and then by treatment, totaling 48 values/measure. As microclimate data were measured in each pen, 24-h data were only summarized by treatment totaling 48 values/measure. Using these data, we tested the effects of treatment for all the dependent variables on mixed models (PROC MIXED). Each model used variance 
Table 1. Summary (daily averages of mean, minimum, and maximum) of weather conditions during 24-h and spray cycling period (0815 to $2330 \mathrm{~h}$ )

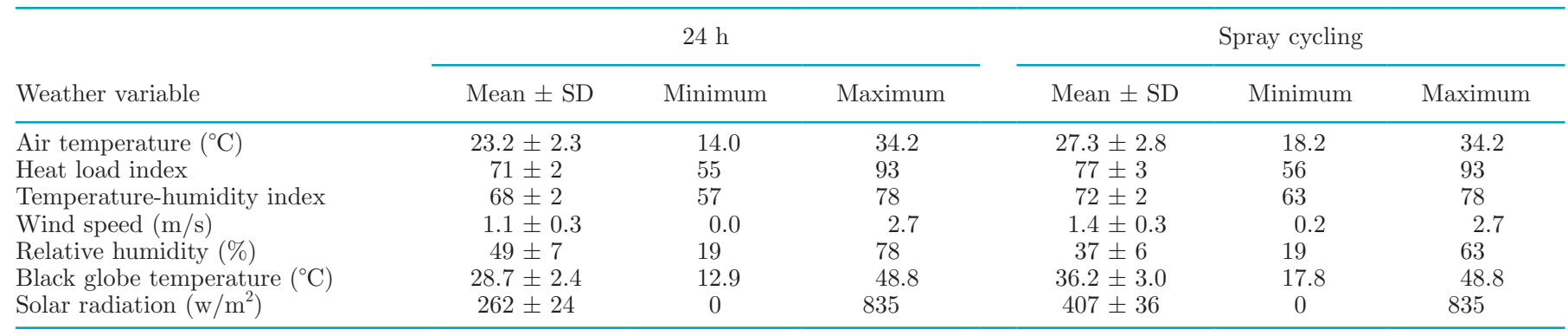

components as the covariance structure, with fixed effects for frequency, flow rates, and their interaction (all included in the CLASS statement), and cow pair was included as a random effect (Equation [1]). Degrees of freedom were estimated using containment method ( $\mathrm{df}$ test $=1$, df error $=33$ ). Pairwise comparisons were made using PDIFF statement and were adjusted using the TUKEY statement.

Similar models were used to evaluate treatment by weather (daily means of AT, THI, WS, and HLI; all treated as a fixed terms) interactions on all measures using daily pair averages (totaling 140 measurements). Each model used variance components as the covariance structure, with fixed effects for weather variable, frequency, flow rates, and all their interactions, and cow pair was included as a random effect (Equation [2]). Degrees of freedom were estimated using the containment method ( $\mathrm{df}$ test $=1$, df error $=121$; except milk yield: $\mathrm{df}$ error $=102)$. Least squares means of slopes (i.e., the magnitude of change in each physiological or behavioral measure per unit increase of each weather variable) were obtained using the ESTIMATE statement.

Whenever biologically relevant or $P<0.1$ in the 24 -h analysis, we analyzed microclimate, behavioral, and physiological data using averages obtained from the spray cycling period (i.e., 0815 to $2330 \mathrm{~h}$ ) or by hour $(0$ to $23 \mathrm{~h})$. Averages were obtained using the same method as described above, and generated 48 values/ measure that were analyzed with separate mixed models for the spray cycling period and each hour, respectively. This approach was used to identify potential treatment differences masked when comparing 24-h averages, especially because the spray cycling period consisted of $15 \mathrm{~h} / \mathrm{d}$. For these analyses we used the same models as described for comparing 24-h averages, adding the by hour statement, for the hourly analyses.

The mathematical equations used are as follows:

$$
\mathrm{Y}_{\mathrm{ijk}}=\mu+\mathrm{F}_{\mathrm{i}}+\mathrm{Fr}_{\mathrm{j}}+(\mathrm{FFr})_{\mathrm{ij}}+\mathrm{P}_{\mathrm{k}}+\mathrm{e}_{\mathrm{ijk}} \text {, }
$$

$$
\begin{aligned}
\mathrm{Y}_{\mathrm{ijkl}} & =\mu+\mathrm{F}_{\mathrm{i}}+\mathrm{Fr}_{\mathrm{j}}+(\mathrm{FFr})_{\mathrm{ij}}+\mathrm{W}_{\mathrm{l}}+(\mathrm{FW})_{\mathrm{il}} \\
& +(\mathrm{FrW})_{\mathrm{jl}}+(\mathrm{FFrW})_{\mathrm{ijl}}+\mathrm{P}_{\mathrm{k}}+\mathrm{e}_{\mathrm{ijk} \mathrm{k}},
\end{aligned}
$$

where $Y_{\mathrm{ijk}}$ and $Y_{\mathrm{ijkl}}$ are milk production or responses to heat load (behavioral or physiological), $\mu$ is the overall mean, $F_{i}$ is the fixed effect of the ith spray flow rate ( $\mathrm{i}=3.3$ or $4.9 \mathrm{~L} / \mathrm{min}$ ), $\mathrm{Fr}_{\mathrm{j}}$ is the fixed effect of the $\mathrm{jth}$ spray frequency $(\mathrm{j}=$ low or high $), \mathrm{P}_{\mathrm{k}}$ is the random effect of kth cow pair $(k=1, \ldots, 12), \mathrm{W}_{\mathrm{l}}$ is the fixed effect of the lth daily weather $(1=1, \ldots, 140)$, and $\mathrm{e}_{\mathrm{ijk}}$ and $\mathrm{e}_{\mathrm{ijkl}}$ are the residual terms, including the random error. Values within parentheses represent interactions of fixed effects.

\section{RESULTS}

\section{Weather and Microclimate}

Mean weather conditions for the 24-h and spray cycling period (0815 to $2330 \mathrm{~h}$ ) are described in Table 1. No rainfall was recorded during this period.

Over $24 \mathrm{~h}$, feed bunk AT averaged $21.7^{\circ} \mathrm{C}$ and it was not affected by flow rate, spray timing, or their interaction $(P>0.61)$. However, during the spray cycling period, spraying cows less often reduced feed bunk AT (high vs. low frequency: 25.1 vs. $23.7 \pm 0.4^{\circ} \mathrm{C} ; P=$ 0.01 ). Lying area AT averaged $24.3 \pm 1.1^{\circ} \mathrm{C}$ and 28.5 $\pm 1.5^{\circ} \mathrm{C}$ during the 24 - $\mathrm{h}$ and spray cycling period, respectively.

Nozzle water temperature averaged $( \pm \mathrm{SD}) 21.9 \pm$ $2.6^{\circ} \mathrm{C}$ at $0815 \mathrm{~h}$, and $27.6 \pm 2.8^{\circ} \mathrm{C}$ at $1645 \mathrm{~h}$. Flow rates throughout the day (0900 to $1945 \mathrm{~h}$ ) ranged from 2.8 to $3.4 \mathrm{~L} / \mathrm{min}$ and 4.0 to $5.0 \mathrm{~L} / \mathrm{min}$ for spray nozzles set to deliver 3.3 or $4.9 \mathrm{~L}$ of water/min, respectively.

\section{Behavioral and Physiological Responses to Heat Load}

Overall, spray timing, flow rates, and their interaction did not affect RR or behavior (Table 2). Body temperature tended to be affected only by flow rate. 
Lying Behavior. Cows were observed lying down, on average, $10 \pm 1$ times/d, totaling $12.6 \pm 0.4 \mathrm{~h} / \mathrm{d}$ of lying regardless of treatment $(P>0.13)$. The duration of each lying event ranged from 77 to $84 \pm 5 \mathrm{~min} /$ bout. Although bout length tended to be affected by treatment (flow $\times$ frequency, $P=0.05$ ), no differences were found across treatments in the adjusted pairwise analysis $(P>0.17)$.

Use of the Feed Bunk and Neighboring Areas. Overall, neither spray timing nor flow rates affected how cows used the feed bunk (area A) or the space near it (area $\mathrm{B}, P>0.12$ ). Cows spent, on average, $5.8 \pm$ $0.3 \mathrm{~h} / \mathrm{d}$ in the feed bunk (area A), which was divided in $16 \pm 1$ bouts of $23 \pm 2$ min each. In the spray cycling period, cows sprayed less often tended to have longer bouts ( 26 vs. $24 \pm 2 \mathrm{~min} /$ bout; $P=0.05$ ), but this difference did not affect the total time spent in this area nor the number of visits $(P>0.24)$. Hourly time spent in the feed bunk (area A) is described in Figure 2a. On average, cows spent $22 \pm 2 \mathrm{~min} / \mathrm{d}$ in the space near the feed bunk (area B). The total time was divided in $30 \pm$ 2 visits of $<1 \pm 0$ min each.

Feeding Activity. Of the time cows were recorded in the feed bunk (area A), they were feeding in, on average, from 77 to $79 \pm 3 \%$ of the observations regardless of treatment $(P>0.40)$. Throughout the day, hourly feeding activity ranged (mean \pm SD) from $52 \pm$ 2 to $94 \pm 3 \%$ of the observations (Figure $2 \mathrm{~b}$ ).

Respiration Rates. Air temperature averaged $( \pm \mathrm{SD}) 29.7 \pm 4.6^{\circ} \mathrm{C}$, when $\mathrm{RR}$ was recorded. The flow rate and timing did not affect daily $\mathrm{RR}$ averages $(P$ $>0.22$ ), which ranged from 57 to $59 \pm 3$ breaths/min across treatments. Throughout the day, RR averages ranged from 49 to 65 breaths/min across treatments (Figure 2c). Among individual cows, RR ranged from 28 to 101 breaths/min throughout the study.
Body Temperature. Spray frequency did not affect $\mathrm{BT}$ in this experiment $(P>0.22)$. When using the higher flow rate, daily $\mathrm{BT}$ average tended to be $0.1^{\circ} \mathrm{C}$ lower in comparison to $3.3 \mathrm{~L} / \mathrm{min}(P=0.08 ; 38.6$ vs. $\left.38.7 \pm 0.1^{\circ} \mathrm{C}\right)$. These differences were more marked in the spray cycling period $(P=0.03)$, especially between 1100 and $2200 \mathrm{~h}$ (Figure 2d).

\section{Milk Production}

Milk yield tended to increase by $1.5 \mathrm{~kg} / \mathrm{d}$ when spraying cows at higher flow rates $(P=0.07 ; 37.8$ vs. $36.3 \pm$ $1.1 \mathrm{~kg} / \mathrm{d})$. Neither spray frequency nor its interaction with flow rates affected milk production $(P>0.69)$.

\section{Weather Effects}

Body temperature, RR, and time spent at the feed bunk increased on warmer days (AT, HLI, and THI) and decreased on windier days, whereas lying time and feeding activity followed opposite patterns (Table 3). The one exception was that feeding tended to increase on windier days $(P=0.06)$. Milk production was not affected by weather on the previous day. No treatment by weather interactions were found for any of the dependent variables tested in this study.

\section{DISCUSSION}

In this study, all cows were cool regardless of the treatment applied. Contrary to what we expected, spraying cows less often created a cooler microclimate in the feed bunk area, but this did not affect heat load responses or milk production in cattle. Using higher flow rates (4.9 vs. $3.3 \mathrm{~L} / \mathrm{min}$ ) reduced BT more markedly when water was cycling, especially between 1100

Table 2. Combined effects of spray timing (i.e., frequency, low: 3 min on, 6 min off; or high: 1.5 min on, 3 min off) and flow rates (3.3 or 4.9 $\mathrm{L} / \mathrm{min}$ ) on cattle behavior, expressed as LSM \pm SEM

\begin{tabular}{|c|c|c|c|c|c|c|c|c|}
\hline \multirow[b]{2}{*}{ Behavior } & \multicolumn{5}{|c|}{ Treatment: flow $\times$ frequency } & \multicolumn{3}{|c|}{ Effect } \\
\hline & 4.9 high & 4.9 low & 3.3 high & 3.3 low & SEM & Flow & Frequency & Flow $\times$ frequency \\
\hline Total time $(\mathrm{h} / \mathrm{d})$ & 5.7 & 5.7 & 5.8 & 5.9 & 0.3 & 0.96 & 0.63 & 0.98 \\
\hline Visits (number/d) & 17 & 15 & 17 & 17 & 1 & 0.44 & 0.31 & 0.15 \\
\hline Duration of each visit (min) & 22 & 25 & 23 & 23 & 2 & 0.12 & 0.71 & 0.12 \\
\hline \multicolumn{9}{|l|}{ Near the feed bunk (area B) } \\
\hline Duration of each visit (min) & $<1$ & $<1$ & $<1$ & $<1$ & 0 & 0.60 & 0.30 & 0.49 \\
\hline \multicolumn{9}{|l|}{ Lying down } \\
\hline Total time $(\mathrm{h} / \mathrm{d})$ & 12.5 & 12.8 & 12.7 & 12.5 & 0.4 & 0.84 & 0.90 & 0.33 \\
\hline Events (no./d) & 10 & 10 & 10 & 10 & 1 & 0.13 & 0.20 & 0.33 \\
\hline Bout duration (min) & 77 & 80 & 84 & 77 & 5 & 0.38 & 0.43 & 0.05 \\
\hline
\end{tabular}


a)

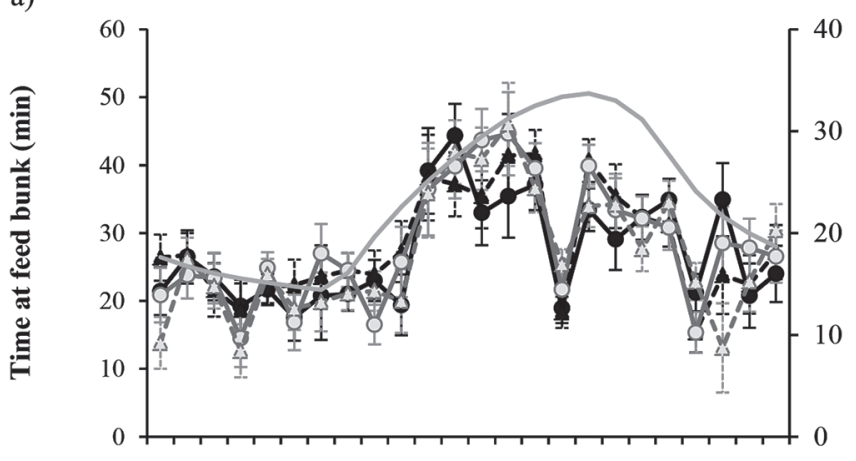

b)

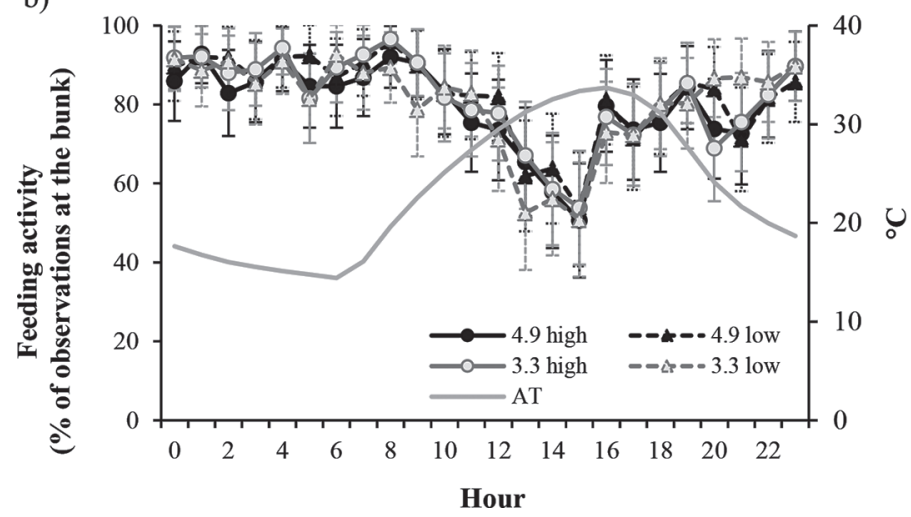

c)

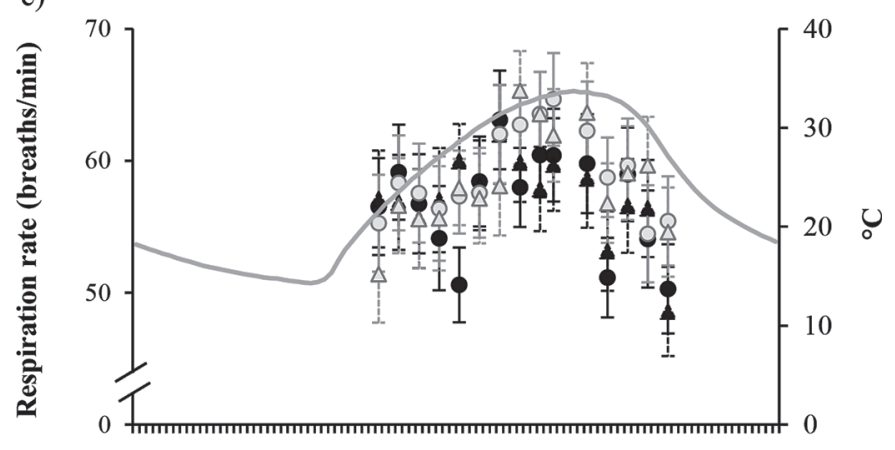

d)

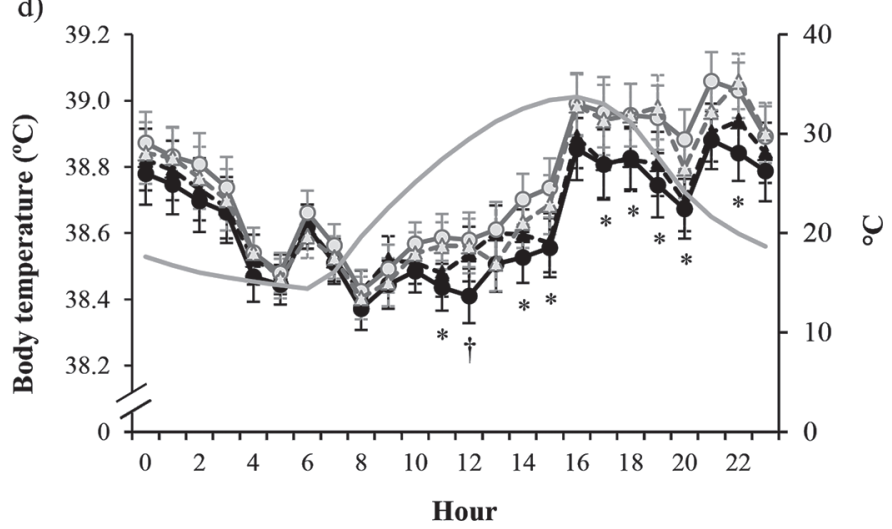

Figure 2. Least squares means \pm SEM of (a) time spent at the feed bunk (area A), (b) $\%$ of the observations at the feed bunk (area A) feeding, (c) respiration rate, and (d) body temperature in response to combined effects of spray timing (i.e., frequency, low: 3 min on, 6 min off; or high: $1.5 \mathrm{~min}$ on, $3 \mathrm{~min}$ off) and flow rates $\left(3.3\right.$ or $4.9 \mathrm{~L} / \mathrm{min}$ ). Hourly mean air temperature (AT, $\left.{ }^{\circ} \mathrm{C}\right)$ is indicated with solid gray lines on the secondary y-axis. Flow differences are indicated using $\left(^{*}\right)$ when $P<0.05$, and $(\dagger)$ when $P<0.09$.

and $2200 \mathrm{~h}$, and tended to improve milk production, but the biological significance of these small differences is unclear.

\section{Cattle Behavior Was Not Affected by Spray Timing or Flow Rates}

Although weather affected all behavioral parameters evaluated, cows spent a fair amount of time lying down $(12.5 \mathrm{~h} / \mathrm{d})$ and in the feed bunk area $(5.8 \mathrm{~h} / \mathrm{d})$. These values are comparable to other studies conducted in cooler weather (described below). In addition, cows were recorded feeding in $\sim 80 \%$ of the observations at the feed bunk area. The latter result indicates cows spent little time standing in the feed bunk area only to obtain cooling.

Use of the Feed Bunk and Neighboring Areas. The microclimate at the feed bunk area where soakers were provided was $\geq 2.9^{\circ} \mathrm{C}$ cooler in comparison to lying and open areas. Other studies have shown similar outcomes (Mader et al., 2007; Chen et al., 2013; Tresoldi et al., 2017). Cows used the space near the feed bunk (area B) primarily for transitions. They only spent about 20 $\mathrm{min} / \mathrm{d}$ in this area, with each event usually lasting less

Table 3. Relationship between behavior, physiology, and weather variables using daily mean values ${ }^{1}$

\begin{tabular}{|c|c|c|c|c|c|}
\hline Weather variable & $\begin{array}{l}\text { Body temperature } \\
\qquad\left({ }^{\circ} \mathrm{C}\right)\end{array}$ & $\begin{array}{c}\text { Respiration rate } \\
\text { (breaths/min) }\end{array}$ & $\begin{array}{l}\text { Time at feed bunk } \\
(\min / \mathrm{d})\end{array}$ & $\begin{array}{l}\text { Time lying down } \\
(\mathrm{min} / \mathrm{d})\end{array}$ & $\begin{array}{c}\text { Feeding } \\
\text { (\% of observations) }\end{array}$ \\
\hline Air temperature $\left({ }^{\circ} \mathrm{C}\right)$ & 0.05 & 2 & 15 & -22 & -3 \\
\hline Temperature-humidity index & 0.05 & 2 & 14 & -21 & -3 \\
\hline Wind speed $(\mathrm{m} / \mathrm{s})$ & -0.05 & -2 & -14 & 23 & 1 \\
\hline
\end{tabular}

${ }^{1}$ Values reported as LSM of slopes (i.e., magnitude of change in each physiological or behavioral measure per unit increase of each weather variable). All interactions $P \leq 0.05$, except the feeding (\% of observations while cows were observed at the feed bunk area) $\times$ wind speed was $P=$ 0.06 . 
than $1 \mathrm{~min}$. As bout length was relatively short, it is unlikely cows were using this area for cooling.

On average, cows spent a similar amount of time in the feed bunk area, compared with studies conducted in cooler conditions ( 5.8 vs. $\geq 5.2 \mathrm{~h} / \mathrm{d}$; DeVries et al., 2003; Tucker et al., 2006) or when spraying cows 24 $\mathrm{h} / \mathrm{d}$ using flow rates of 1.3 or $4.9 \mathrm{~L} / \mathrm{min}$ (Chen et al., 2016b). In contrast, cows sprayed $24 \mathrm{~h} / \mathrm{d}$ using flow rates of $3.3 \mathrm{~L} / \mathrm{min}$ (Chen et al., 2013) used the feed bunk area for longer $(7.8 \mathrm{~h} / \mathrm{d})$, they spent more than $50 \%$ of their time not feeding, indicating cows were using this area mostly for cooling. These differences could be driven by weather (maximum AT averaged $2^{\circ} \mathrm{C}$ higher than in this study), and spray timing (5 min on, 10 min off). Both factors can affect use of cooling resources and their effectiveness (Chen et al., 2016a; Tresoldi et al., 2018).

In our study, cows seemed to use the feed bunk area to obtain cooling during the afternoon as they fed less while at the bunk in comparison to early morning. However, the time they spent in this area to obtain cooling only was lower compared with what was found by Chen et al. ( $2013 ; \geq 50 \%$ vs. $20 \%$ in our study). Our feeding results are similar to those described in other studies conducted in Canadian freestall barns, where no cooling strategies were provided at the feedline (e.g., 81-87\%, Fregonesi et al., 2004; Tucker et al., 2006). If cows are effectively cooled while they feed, other aspects of their welfare can also be improved. For example, it can reduce the time cows stand on wet concrete, reducing the risks for hoof-related problems (Vanegas et al., 2006).

Weather affected both use of the feed bunk area and feeding activity. Throughout the trial, for every $1^{\circ} \mathrm{C}$ increase in mean daily AT, cows spent an extra $15 \mathrm{~min} / \mathrm{d}$ in the feed bunk area and feeding activity was reduced by 3\%. Other studies (Parola et al., 2012; Chen et al., 2013, 2016b) have also shown that cows use spray to minimize the negative effects of the heat load on warmer days. However, spending more time at the feed bunk area on warmer days did not prevent changes in feeding activity in our study, contrary to what was described by Chen et al. (2013). On the other hand, windier days had a yet another effect on cattle behavior: cows spent less time at the bunk and tended to increase time feeding. Mathematical models have shown that total heat losses increase with air velocity and decrease with $\mathrm{RH}$ due to their effects on the vapor concentration gradient between the skin surface and the air (Kimmel et al., 1991; Gebremedhin and Wu, 2002; Gebremedhin et al., 2008). Thus, cooling benefits in this study could be greater than expected in high RH climates.

Cows spent $23 \mathrm{~min}$, on average, for every visit to the feed bunk area. Similar short duration bouts were described in other studies conducted in freestall barns (Tucker et al., 2006; Chen et al., 2016b). Despite our cows spending more time in the feed bunk during the afternoon, bout duration in our study was not as long as bout duration reported for commercial drylot dairies (49 min; Tresoldi et al., 2016). We speculate these differences could be due to warmer weather during our 2016 study (maximum AT was $2^{\circ} \mathrm{C}$ higher than in this study), and potentially because the distance between lying and feed bunk areas was shorter than in drylots. Other studies have shown that longer walking distances increase heat load in cattle (Schütz et al., 2011) and reduce their preference for resources (Motupalli et al., 2014). In this study, the short distance $(\sim 7 \mathrm{~m})$ between lying and feed bunk areas likely encouraged cows to move back and forth as they needed.

Contrary to what we expected and found in another study (Tresoldi et al., 2018), when we sprayed cows less often, they spent 2 min longer at each visit to the feed bunk while the spray was cycling. Although the biological relevance of such small difference is unclear, this could be driven by the cooler microclimate when compared with higher spray frequency $\left(25.1\right.$ vs. $\left.23.7^{\circ} \mathrm{C}\right)$. The cooler microclimate, however, did not affect overall time spent in the feed bunk area nor the heat abatement effectiveness of this strategy.

Lying Activity. Cows rested for $12.5 \mathrm{~h} / \mathrm{d}$, on average, which was divided into 80-min bouts. Time lying and bout duration were both comparable to other studies where cows had access to soakers during summer (Chen et al., 2016b), or sand-bedded stalls in Canada and the Midwest during cooler weather (Gomez and Cook, 2010; Solano et al., 2016). Our cows spent an extra $2 \mathrm{~h}$ lying down compared with cows housed in California freestalls assessed during spring (Ito et al., 2014). This difference seems to be driven by longer bouts found in our study ( $\sim 80$ vs. $60 \mathrm{~min})$. Neither spray timing nor flow rate affected lying behavior in our study. When examining different flow rates (1.3 vs. $4.9 \mathrm{~L} / \mathrm{min}$ ), Chen et al. (2016b) also did not find any changes in lying behavior. On warmer days, cows in our study spent less time lying down. For every $1^{\circ} \mathrm{C}$ increase in mean daily $\mathrm{AT}$, lying time was reduced in about $22 \mathrm{~min} / \mathrm{d}$, similar to what was found by Chen et al. (2016b).

\section{Physiological Responses to Heat Load and Production Tended To Be Affected by Flow Rate But Not Spray Timing}

Regardless of treatment, all cows were relatively cool in this study: BT and RR were at the lower range of values described in the literature. When using the same water volume, spray timing had no effect on production 
and physiological responses to heat load. Using higher flow rates tended to improve cooling and milk production.

Body Temperature. Over $24 \mathrm{~h}$, the highest hourly BT average, $39.1^{\circ} \mathrm{C}$, occurred around 2100 to 2200 $\mathrm{h}$. This temperature is lower than fever thresholds described in the literature (e.g., $\geq 39.3^{\circ} \mathrm{C}$; Benzaquen et al., 2007; Reece, 2015), indicating that cows likely did not experience hyperthermia in our study. This BT peak is also lower than found for cows that had access to shade only in other studies conducted during summer (range: 39.4 to $40.0^{\circ} \mathrm{C}$; Brouk et al., 2003; Chen et al., 2013, 2016b), suggesting that these treatments effectively reduced heat load. In addition, our daily BT averages $\left(\leq 38.7^{\circ} \mathrm{C}\right)$ were similar to other studies that evaluated the effects of similar flow rates (e.g., $\leq 38.8^{\circ} \mathrm{C}$; Chen et al., 2013, 2016b, when using 3.3 and $4.9 \mathrm{~L} / \mathrm{min}$, respectively). However, in these other studies, cows had access to spray water $24 \mathrm{~h} / \mathrm{d}$, resulting in overall higher water use per nozzle compared with the current study (an extra $\sim 190$ and $370 \mathrm{~L} / \mathrm{d}$, respectively, for Chen et al., 2013, 2016b).

Changes in the magnitude of BT as a function of mean daily AT and WS are similar to those described by Chen et al. (2016b) and in our previous work (Tresoldi et al., 2018) when using nozzles delivering $4.9 \mathrm{~L}$ of water $/ \mathrm{min}\left(0.05^{\circ} \mathrm{C}\right.$ for each $1^{\circ} \mathrm{C}$ increase in $\mathrm{AT}$ and $-0.04^{\circ} \mathrm{C}$ for each $1 \mathrm{~m} / \mathrm{s}$ increase in WS), but lower than when cows had access to shade only (Chen et al., 2013, 2016b). Some work has shown the benefits of windier days on cooling when cows are sprayed (Chen et al., 2015, 2016b; Tresoldi et al., 2018), and others have suggested than fans improve cooling effectiveness of sprayed water. However, these studies either suffer from pseudo-replication (Turner et al., 1992; Lin et al., 1998) or their statistical procedures are not clearly described (Hillmann et al., 2001; Brouk et al., 2003). Taken together, these findings suggest that increasing barn airflow may improve water cooling efficiency. However, more research is needed to identify strategies that strike an efficient balance between cow cooling and resource use.

Contrary to what we expected, only flow rates affected BT. However, the biological significance of such small differences $\left(\sim 0.1^{\circ} \mathrm{C}\right)$ is unclear, especially given that all cows were relatively cool throughout the day. Others have found no differences in BT when comparing flow rates $\geq 1.3 \mathrm{~L} / \mathrm{min}$. However, these results can be attributed to differences in the experimental design among studies. For example, differences across all the treatments tested were at least $0.3^{\circ} \mathrm{C}$ (as it included a shade only treatment; Chen et al., 2016b) or their sample size was smaller than ours $(\mathrm{n}=3$; Means et al., 1992). In addition, timing had no effect on BT, likely because we used the same overall water volume for the 2 frequencies tested. Others have found that spray timing affects cow cooling when it also results in higher water volume (Flamenbaum et al., 1986; Brouk et al., 2003; Tresoldi et al., 2018), but this yet has to be tested in loose housing systems.

Respiration Rates. Throughout the day RR was, on average, 65 breaths/min at the most, which compares to the lower range found on California farms in summer (Tresoldi et al., 2017). In comparison to other spray studies where cows had access $24 \mathrm{~h} / \mathrm{d}$, our mean values are intermediary. They are $>10$ breaths/ min lower than described by Parola et al. (2012) when spraying unshaded beef cattle, and almost 10 breaths/ min higher than reported by Chen et al. (2013) for dairy cattle. The lowest individual RR recorded was similar to what we found in commercial drylots (28 vs. 25 breaths/min), the upper range differed almost 50 breaths/min (101 in this study vs. 147 breaths/min, Tresoldi et al., 2017). However, this difference among studies can be attributed to variation in weather, cooling strategies, and individuals. In this study, RR increased 2 breaths $/ \mathrm{min}$ for each $1^{\circ} \mathrm{C}$ increase in mean daily AT and decreased in the same proportion in every $1 \mathrm{~m} / \mathrm{s}$ increase in mean daily WS. Other studies have also shown that RR increases with AT (Kabuga, 1992; Parola et al., 2012).

In this study, neither flow rate nor spray timing affected RR. The lack of flow rate effect on RR was shown previously by Means et al. (1992) when using nozzles delivering $\geq 5.2 \mathrm{~L} / \mathrm{min}$. When forcing cows to use soakers for $45 \mathrm{~min}$, we found that spraying cows more often only tended to reduce RR (but not BT), and the difference was $<10$ breaths/min (Tresoldi et al., 2018). In that study, we speculated that RR is a more plastic or sensitive response to direct spray than BT, for example, as RR changes quickly (also observed by Chen et al., 2015).

Milk Production. Cows sprayed using higher flow rates tended to produce more milk. In this study, this difference can be only explained by the reduced BT in the $4.9 \mathrm{~L} / \mathrm{min}$ treatments. However, it is unlikely to be the only driver of change because all cows were relatively cool throughout this study. The mechanism, and therefore the repeatability of this difference, is unclear. Similar to what described for BT, other studies have found no differences in milk production when comparing flow rates $\geq 1.3 \mathrm{~L} / \mathrm{min}$ (Means et al., 1992; Chen et al., 2016b).

\section{CONCLUSIONS}

Altogether, our results suggest that the spray strategies we used effectively cooled cows. Using spray noz- 
zles delivering $4.9 \mathrm{~L} / \mathrm{min}$ had poor efficiency, as adding more water did not result in more biologically relevant cooling. In this study, spray timing did not affect production nor behavioral and physiological responses to heat load when using the same water volume.

\section{ACKNOWLEDGMENTS}

We are grateful to those who assisted with data collection: Lucas Batista Saraiva da Costa (supported by the Science Without Borders Program, Brasilia, Brazil), Adolfo Porras Madrigal, Bradley Whelchel, Tony Phan, Mia Cotero, Mirella Lopez, Ariana Amador, Carissa Chow, Emily Chen, Kareen Mendonza, Niloufar Keramat, Shayna Doyle, Thanh Ngo, Angela Sun, Brenda Dominguez, Caillan Bower, Christina Lee, Elodie Fabre, Janelle Park, Josephine Yao, Kaitlyn Yapjoco, Kevin Lin, Marion Coste, Neena Lynton, Rene Cuellar, and Sheron Pak (all affiliated with University of California, Davis) at the time of the study. Many thanks also go to Doug Gisi, Maria Patino, and the staff and interns of the University of California-Davis Dairy Teaching and Research Facility. We are thankful to Joy Mench, Neil Willits, Daniel Sehnert, Frank Sauers, Jose Villasenor, Blair Downey, and Adrien Durand-Petiteville (all affiliated with University of California-Davis at the time of the study). We gratefully acknowledge the financial support of Coordenação de Aperfeiçoamento de Pessoal de Nível Superior (CAPES, Brasilia, Brazil; process BEX 0764/12-4, awarded to G. Tresoldi), Jastro Shields Award (Davis, CA), USDA multi-state research project W2173 and W3173 (Washington, DC), and the infrastructure support of the Department of Animal Science, and the College of Agricultural and Environmental Sciences of the University of California, Davis.

\section{REFERENCES}

Anderson, S. D., B. J. Bradford, J. P. Harner, C. B. Tucker, C. Y. Choi, J. D. Allen, L. W. Hall, S. Rungruang, R. J. Collier, and J. F. Smith. 2013. Effects of adjustable and stationary fans with misters on core body temperature and lying behavior of lactating dairy cows in a semiarid climate. J. Dairy Sci. 96:4738-4750. https: //doi.org/10.3168/jds.2012-6401.

Benzaquen, M. E., C. A. Risco, L. F. Archbald, P. Melendez, M. J. Thatcher, and W. W. Thatcher. 2007. Rectal temperature, calving-related factors, and the incidence of puerperal metritis in postpartum dairy cows. J. Dairy Sci. 90:2804-2814. https://doi.org/10 .3168/jds.2006-482.

Bohmanova, J., I. Misztal, and J. B. Cole. 2007. Temperature-humidity indices as indicators of milk production losses due to heat stress. J. Dairy Sci. 90:1947-1956. https://doi.org/10.3168/jds.2006-513.

Brouk, M. J., J. F. Smith, and J. P. Harner III. 2003. Effect of sprinkling frequency and airflow on respiration rate, body surface temperature and body temperature of heat stressed dairy cattle. Pages 263-268 in 5th International Dairy Housing, Fort Worth, TX. ASAE, St. Joseph, MI.
Chen, J. M., K. E. Schütz, and C. B. Tucker. 2013. Dairy cows use and prefer feed bunks fitted with sprinklers. J. Dairy Sci. 96:50355045. https://doi.org/10.3168/jds.2012-6282.

Chen, J. M., K. E. Schütz, and C. B. Tucker. 2015. Cooling cows efficiently with sprinklers: Physiological responses to water spray. J. Dairy Sci. 98:6925-6938. https://doi.org/10.3168/jds.2015-9434.

Chen, J. M., K. E. Schütz, and C. B. Tucker. 2016a. Sprinkler flow rate affects dairy cattle preferences, heat load, and insect deterrence behavior. Appl. Anim. Behav. Sci. 182:1-8. https://doi.org/ 10.1016/j.applanim.2016.05.023.

Chen, J. M., K. E. Schütz, and C. B. Tucker. 2016b. Cooling cows efficiently with water spray: Behavioral, physiological, and production responses to sprinklers at the feed bunk. J. Dairy Sci. 99:4607-4618. https://doi.org/10.3168/jds.2015-10714.

Chen, J. M., K. E. Schütz, and C. B. Tucker. 2016c. Sprinkler flow rate affects dairy cattle avoidance of spray to the head, but not overall, in an aversion race. Appl. Anim. Behav. Sci. 179:23-31. https:// doi.org/10.1016/j.applanim.2016.03.007.

Correa-Calderon, A., D. Armstrong, D. Ray, S. DeNise, M. Enns, and C. Howison. 2004. Thermoregulatory responses of Holstein and Brown Swiss heat-stressed dairy cows to two different cooling systems. Int. J. Biometeorol. 48:142-148. https://doi.org/10.1007/ s00484-003-0194-y.

DeVries, T. J., M. A. G. von Keyserlingk, D. M. Weary, and K. A. Beauchemin. 2003. Measuring the feeding behavior of lactating dairy cows in early to peak lactation. J. Dairy Sci. 86:3354-3361. https://doi.org/10.3168/jds.S0022-0302(03)73938-1.

Flamenbaum, I., D. Wolfenson, M. Mamen, and A. Berman. 1986. Cooling dairy cattle by a combination of sprinkling and forced ventilation and its implementation in the shelter system. J. Dairy Sci. 69:3140-3147. https://doi.org/10.3168/jds.S0022-0302(86)80778 $-0$.

Fregonesi, J. A., C. B. Tucker, D. M. Weary, F. C. Flower, and T. Vittie. 2004. Effect of rubber flooring in front of the feed bunk on the time budgets of dairy cattle. J. Dairy Sci. 87:1203-1207. https:// doi.org/10.3168/jds.S0022-0302(04)73270-1.

Gaughan, J. B., and T. L. Mader. 2014. Body temperature and respiratory dynamics in un-shaded beef cattle. Int. J. Biometeorol. 58:1443-1450. https://doi.org/10.1007/s00484-013-0746-8.

Gaughan, J. B., T. L. Mader, S. M. Holt, and A. Lisle. 2008. A new heat load index for feedlot cattle. J. Anim. Sci. 86:226-234. https: //doi.org/10.2527/jas.2007-0305.

Gebremedhin, K. G., P. E. Hillman, C. N. Lee, R. J. Collier, S. Willard, J. D. Arthington, and T. M. Brown-Brandl. 2008. Sweating rates of dairy cows and beef heifers in hot conditions. Trans. ASABE 51:2167-2178. https://doi.org/10.13031/2013.25397.

Gebremedhin, K. G., and B. Wu. 2002. Simulation of sensible and latent heat losses from wet-skin surface and fur layer. J. Therm. Biol. 27:291-297. https://doi.org/10.1016/S0306-4565(01)00091-2.

Gomez, A., and N. B. Cook. 2010. Time budgets of lactating dairy cattle in commercial freestall herds. J. Dairy Sci. 93:5772-5781. https://doi.org/10.3168/jds.2010-3436.

Hillmann, P. E., K. G. Gebremedhin, A. Parkhurst, J. Fuquay, and S. Willard. 2001. Evaporative and convective cooling of cows in a hot and humid environment. Pages 343-350 in 6th International Symposium of Livestock Environment, Louisville, KY. ASAE, Louisville, KY.

Huang, C., S. Tsuruta, J. K. Bertrand, I. Misztal, T. J. Lawlor, and J. S. Clay. 2009. Trends for conception rate of Holsteins over time in the southeastern United States. J. Dairy Sci. 92:4641-4647. https: //doi.org/10.3168/jds.2008-1982.

Ito, K., N. Chapinal, D. M. Weary, and M. A. G. von Keyserlingk. 2014. Associations between herd-level factors and lying behavior of freestall-housed dairy cows. J. Dairy Sci. 97:2081-2089. https:/ /doi.org/10.3168/jds.2013-6861.

Kabuga, J. D. 1992. The influence of thermal conditions on rectal temperature, respiration rate and pulse rate of lactating Holstein-Friesian cows in the humid tropics. Int. J. Biometeorol. 36:146-150. https://doi.org/10.1007/BF01224817. 
Kelly, C. F., and T. E. Bond. 1971. Bioclimatic factors and their measurement. Page 77 in A Guide to Environmental Research on Animals. National Academies Press, Washington, DC.

Kendall, P. E., G. A. Verkerk, J. R. Webster, and C. B. Tucker. 2007. Sprinklers and shade cool cows and reduce insect-avoidance behavior in pasture-based dairy systems. J. Dairy Sci. 90:3671-3680. https://doi.org/10.3168/jds.2006-766.

Kimmel, E., H. Arkin, D. Broday, and A. Berman. 1991. A model of evaporative cooling in a wetted hide. J. Agric. Eng. Res. 49:227241. https://doi.org/10.1016/0021-8634(91)80041-C.

Lin, J. C., B. R. Moss, J. L. Koon, C. A. Flood, R. C. Smith III, K. A. Cummings, and D. A. Coleman. 1998. Comparison of various fan, sprinkler, ans mister systems in reducing heat stress in dairy cows. Appl. Eng. Agric. 14:177-182. https://doi.org/10.13031/ 2013.19370.

Mader, T. L., M. S. Davis, and J. B. Gaughan. 2007. Effect of sprinkling on feedlot microclimate and cattle behavior. Int. J. Biometeorol. 51:541-551. https://doi.org/10.1007/s00484-007-0093-8.

Means, S. L., R. A. Bucklin, R. A. Nordstedt, D. K. Beede, D. R. Bray, C. J. Wilcox, and W. K. Sanchez. 1992. Water application rates for sprinklers and fan dairy cooling system in hot, humid climates. Trans. ASAE 8:374-378. https://doi.org/10.13031/2013.26080.

Motupalli, P. R., L. A. Sinclair, G. L. Charlton, E. C. Bleach, and S. M. Rutter. 2014. Preference and behavior of lactating dairy cows given free access to pasture at two herbage masses and two distances. J. Anim. Sci. 92:5175-5184. https://doi.org/10.2527/jas $.2014-8046$

Parola, F., E. Hillmann, K. E. Schütz, and C. B. Tucker. 2012. Preferences for overhead sprinklers by naïve beef steers: Test of two nozzle types. Appl. Anim. Behav. Sci. 137:13-22. https://doi.org/ 10.1016/j.applanim.2011.12.010.

Reece, W. O. 2015. Body temperature and its regulation. Pages 149154 in Dukes' Physiology of Domestic Animals. 13th ed. W. O. Reece, ed. Wiley Blackwell, Ithaca, NY.

SAS Institute Inc. 2014. SAS 9.4 Language Reference: Concepts. SAS Institute Inc., Cary, NC.

Schuller, L. K., O. Burfeind, and W. Heuwieser. 2014. Impact of heat stress on conception rate of dairy cows in the moderate climate considering different temperature-humidity index thresholds, periods relative to breeding, and heat load indices. Theriogenology 81:1050-1057. https://doi.org/10.1016/j.theriogenology.2014.01 .029 .

Schütz, K. E., N. R. Cox, and L. R. Matthews. 2008. How important is shade to dairy cattle? Choice between shade or lying following different levels of lying deprivation. Appl. Anim. Behav. Sci. 114:307-318. https://doi.org/10.1016/j.applanim.2008.04.001.

Schütz, K. E., A. R. Rogers, N. R. Cox, and C. B. Tucker. 2009. Dairy cows prefer shade that offers greater protection against solar radiation in summer: Shade use, behaviour, and body temperature. Appl. Anim. Behav. Sci. 116:28-34. https://doi.org/10.1016/ j.applanim.2008.07.005.

Schütz, K. E., A. R. Rogers, N. R. Cox, J. R. Webster, and C. B. Tucker. 2011. Dairy cattle prefer shade over sprinklers: effects on behavior and physiology. J. Dairy Sci. 94:273-283. https://doi .org/10.3168/jds.2010-3608.
Solano, L., H. W. Barkema, E. A. Pajor, S. Mason, S. J. LeBlanc, C. G. R. Nash, D. B. Haley, D. Pellerin, J. Rushen, A. M. de Passillé, E. Vasseur, and K. Orsel. 2016. Associations between lying behavior and lameness in Canadian Holstein-Friesian cows housed in freestall barns. J. Dairy Sci. 99:2086-2101. https://doi.org/10 $.3168 /$ jds.2015-10336.

St-Pierre, N. R., B. Cobanov, and G. Schnitkey. 2003. Economic losses from heat stress by US livestock industries. J. Dairy Sci. 86:E52E77. https://doi.org/10.3168/jds.S0022-0302(03)74040-5.

Tarazon-Herrera, M., J. T. Huber, J. Santos, H. Mena, L. Nusso, and C. Nussio. 1999. Effects of bovine somatotropin and evaporative cooling plus shade on lactation performance of cows during summer heat stress. J. Dairy Sci. 82:2352-2357. https://doi.org/10 .3168/jds.S0022-0302(99)75485-8.

Tresoldi, G., K. E. Schütz, and C. B. Tucker. 2016. Assessing heat load in drylot dairy cattle: Refining on-farm sampling methodology. J. Dairy Sci. 99:8970-8980. https://doi.org/10.3168/jds.2016-11353.

Tresoldi, G., K. E. Schütz, and C. B. Tucker. 2017. Cow cooling on commercial drylot dairies: A description of 10 farms in California. Calif. Agric. 71:249-255. https://doi.org/10.3733/ca.2017a0042.

Tresoldi, G., K. E. Schütz, and C. B. Tucker. 2018. Cooling cows with sprinklers: Spray duration affects physiological responses to heat load. J. Dairy Sci. 101:4412-4423. https://doi.org/10.3168/ jds.2017-13806.

Tresoldi, G., K. E. Schütz, and C. B. Tucker. 2018. Cooling cows with sprinklers: Timing strategy affects physiological responses to heat load. J. Dairy Sci. 101:11237-11246. https://doi.org/10.3168/jds .2018-14917.

Tucker, C. B., A. R. Rogers, and K. E. Schütz. 2008. Effect of solar radiation on dairy cattle behaviour, use of shade and body temperature in a pasture-based system. Appl. Anim. Behav. Sci. 109:141-154. https://doi.org/10.1016/j.applanim.2007.03.015.

Tucker, C. B., D. M. Weary, A. M. d. Passillé, B. Campbell, and J. Rushen. 2006. Flooring in front of the feed bunk affects feeding behavior and use of freestalls by dairy cows. J. Dairy Sci. 89:20652071. https://doi.org/10.3168/jds.S0022-0302(06)72274-3.

Turner, L. W., J. P. Chastain, R. W. Hemken, R. S. Gates, and W. L. Crist. 1992. Reducing heat stress in dairy cows through sprinkler and fan cooling. Appl. Eng. Agric. 8:251-256. https://doi.org/10 $.13031 / 2013.26218$.

USDA. 2016. Dairy 2014, Dairy cattle management practices in the United States, 2014. USDA, ed. USDA-APHIS-VS-CEAHNAHMS, Fort Collins, CO.

Vanegas, J., M. Overton, S. L. Berry, and W. M. Sischo. 2006. Effect of rubber flooring on claw health in lactating dairy cows housed in free-stall barns. J. Dairy Sci. 89:4251-4258. https://doi.org/10 $.3168 /$ jds.S0022-0302(06)72471-7.

von Keyserlingk, M. A. G., N. P. Martin, C. J. Sniffen, J. P. Harner III, A. D. Wright, and S. I. Smith. 2013. Invited review: Sustainability of the US dairy industry. J. Dairy Sci. 96:5405-5425. https: //doi.org/10.3168/jds.2012-6354.

Wheelock, J. B., R. P. Rhoads, M. J. Vanbaale, S. R. Sanders, and L. H. Baumgard. 2010. Effects of heat stress on energetic metabolism in lactating Holstein cows. J. Dairy Sci. 93:644-655. https://doi .org/10.3168/jds.2009-2295. 